Asociación de Jóvenes Historiadores y Arqueólogos de Murcia

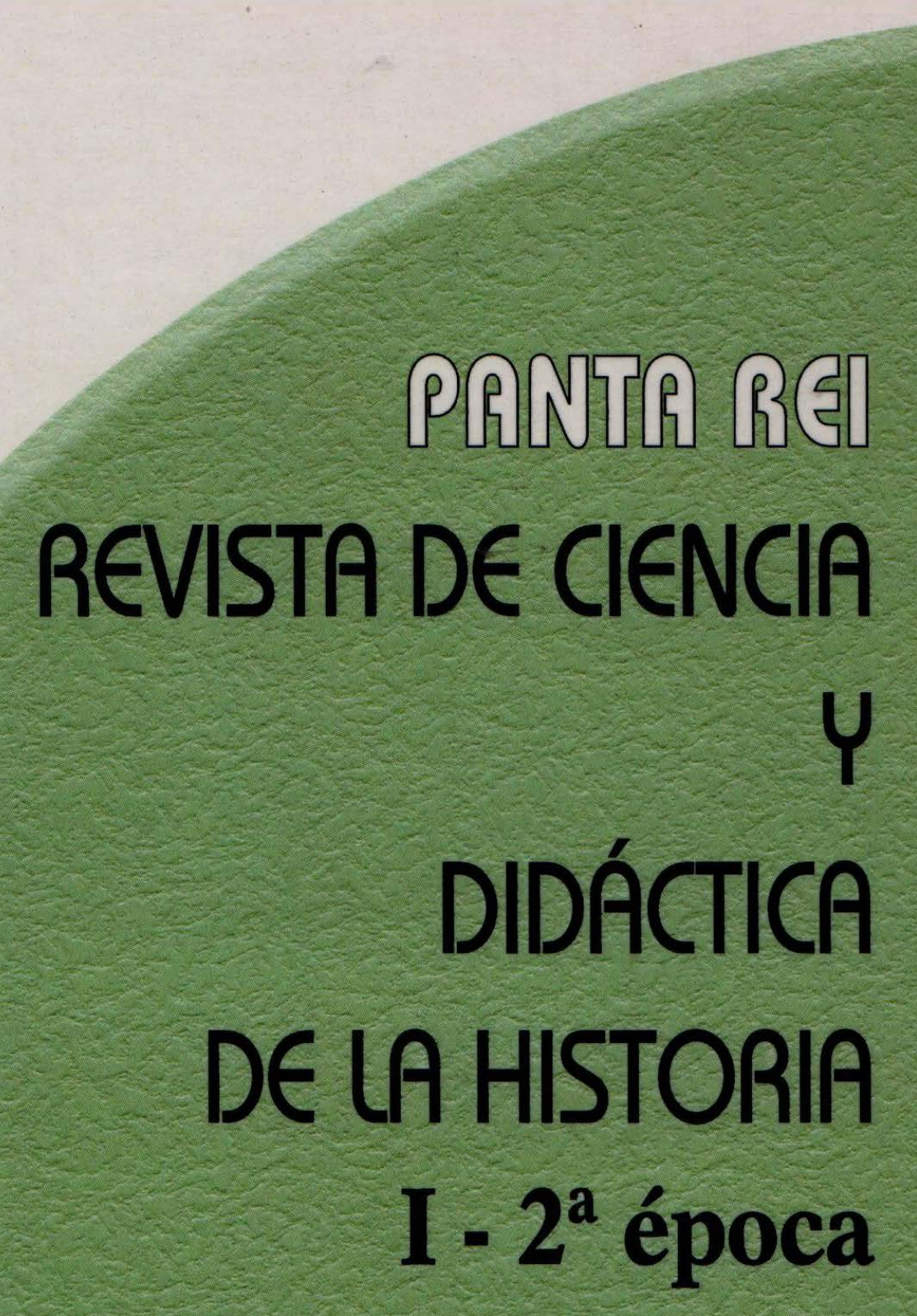

MURCIA 2006 


\title{
LOS SOLDADOS ILIRIOS EN EL EJÉRCITO DE LOS SEVEROS (193-235)
}

\author{
Miguel P. SANCho Gómez
}

\section{Introducción}

Septimio Severo fue proclamado emperador por las legiones de Panonia el nueve de abril de 193, tan pronto como llegó la noticia de la muerte de Pértinax al limes danubiano'. A la situación confusa en todo el Imperio se unió la indignación general en esa zona concreta, donde el Augusto asesinado había sido gobernador no mucho antes, dejando un recuerdo grato y entrañable ${ }^{2}$. El ambicioso e inteligente Severo supo sacar partido rápidamente de la furia que dominaba a sus tropas, y presentándose como el vengador de Pértinax ganó el control de las legiones allí establecidas, compuestas de soldados ilirios.

Cuatro años después, tras derrotar a tres rivales por el Imperio y poner bajo su control todas las provincias romanas desde Siria hasta Britania, se convertía en señor único de Roma y en instaurador de una estirpe de soberanos que iba a dominar de manera incontestable la escena política durante el primer cuarto del siglo III. Asimismo, las reformas realizadas por Septimio Severo y sus sucesores significaron una verdadera revolución en el aspecto político y en el militar, y han sido fuente de controversias hasta hoy en día ${ }^{3}$.

Indudablemente, una gran parte de su éxito en las campañas exteriores, así como los logros contundentes que cosechó en las guerras civiles, se deben principalmente a las fuerzas que comandó, y que desde este momento van a revelarse como las tropas más preparadas y valiosas del ejército romano, para alcanzar su cenit en la época de

1 HERODIANO II 10; II 9, 12-13. DIÓN CASIO, LXXIV 14, 3-4.

2 HERODIANO, II 9, 8-10; En esos momentos Severo se hizo llamar «Severo Pértinax» (HERODIANO II 10,$1 ; 10,9)$.

3 Cf. A. DAUGUET-GAGEY, Septime Sévère: Rome, l'Afrique et l'Orient. Paris, 2000. 
los Emperadores Ilirios, que dirigirán el Imperio durante más de cincuenta años y luego desembocar en la Tetrarquía y en los Segundos Flavios ${ }^{4}$, que en su origen eran del mismo modo instituciones o dinastías ilíricas. No queremos con esto, de ninguna manera, oscurecer o minimizar la soberbia actuación de Severo y sus grandes dotes como estadista y militar, punto demostrado holgadamente por los mismos hechos y reconocido meridianamente por sus contemporáneos 5 . Pero por todo lo mencionado anteriormente, cabe preguntarse por la idiosincrasia y formación de estas unidades, que suministraron de forma prácticamente constante las mejores tropas imperiales hasta bien entrado el siglo $\mathrm{VI}^{6}$.

\section{El soldado ilirio}

El historiador griego Herodiano ${ }^{7}$, sin duda la fuente más importante para el turbulento periodo que va desde la muerte de Marco Aurelio hasta el tiempo de los Gordianos, nos deja una vívida descripción del tipo ilirio común, motivo que resulta muy recurrido en la historiografía de la época, muy dada a las descripciones étnicas, que solían encasillar a los diferentes pueblos dentro de unas virtudes y defectos muy rígidamente aplicados a unos o a otros: «Los hombres de aquella región, físicamente, son altos y muy fuertes, bien dotados para el combate y muy sanguinarios, pero en lo tocante a su inteligencia, son obtusos y cerrados de mollera, si se les dice o hace algo con malicia y engaño». ${ }^{8}$ No es la única ocasión en la que en la Historia de Roma después de la muerte de Marco Aurelio se retrata a un grupo étnico así.

Nuevos ejemplos acerca del carácter y las costumbres de los habitantes de Panonia y el Ilírico pueden ilustrar aún más nuestros conocimientos acerca de estas gentes; sólo cien años después del final de nuestro periodo, y complementándose bastante bien con el testimonio anterior, encontramos la vívida y sentida descripción del emperador Juliano9, que vivió en el siglo IV (331/332-363). Para referirse a él mismo y a sus antepasados, habló así: «...los habitantes de Mesia, situada entre Tracia y Peonia, al borde del Danubio, de donde proviene mi linaje, completamente rústico, austero, inhábil, insensible al amor, perseverante de forma inflexible en sus determinaciones».

\footnotetext{
4 Para ambos periodos, cf. M. CLAUSS, Constantino el Grande y su época. Madrid, 2001; H. A. POHLSANDER, The emperor Constantine. Londres, 2004.

5 HERODIANO III 7, 8; HISTORIA AUGUSTA, Severo 18, 3.

6 De hecho, tanto Justino I (518-527) como Justiniano I (527-565) eran de origen ilirio; esa provincia comenzó a abandonarse desde la llegada en masa de los eslavos entorno a 570.

7 Cf. F. KOLB, Literarische Beziehungen zwischen Cassius Dio, Herodian und der Historia Augusta. Bonn, 1972.

8 HERODIANO, II 9, 11.

9 JULIANO, Discurso de Antioquia, 348d.
} 
Sus sucesores inmediatos en el trono, primero Joviano, y después los hermanos Valente y Valentiniano I, procedieron asimismo de esta parte del Imperio, y el recio físico, acompañado de un carácter fuerte y temperamental, fueron también cualidades del padre de ambos hermanos, Graciano el Mayor, y también de uno de los hijos, Valentiniano ${ }^{10}$. El apetito insaciable también se convirtió en un rasgo común de estas gentes, siendo comprensible que necesitasen grandes cantidades de comida para mantener su físico imponente, de gran tamaño y poderosa musculatura ${ }^{11}$.

\section{Septimio Severo}

Este carácter simple que como hemos visto Herodiano achaca a los ilirios, sería utilizado con mucha astucia por Lucio Septimio Severo, gobernador de Panonia a la sazón, de tal manera que la entrega de las tropas tras su proclamación fue total ${ }^{12}$. Una vez asegurado su poder con la ayuda de su hermano Geta, y tras marchar hacia Roma guarneciendo las provincias que dejaba atrás a su paso ${ }^{13}$, Severo se encontró con una campaña triunfal e inocua tras cruzar los Alpes gracias a la actitud vergonzosa y desganada de Didio Juliano, que no pudo ni supo defender ni Italia ni Roma; muchos juicios poco halagadores fueron vertidos por las fuentes literarias contemporáneas sobre el emperador que ocupaba la capital imperial en ese momento ${ }^{14}$. Al conocer que Severo marchaba hacia él con las legiones ilirias, conociendo perfectamente su fuerza y valía, se llenó de estupor ${ }^{15}$. De hecho, éste se hallaba ya aterrorizado al conocer la nueva de que Severo avanzaba sobre la ciudad, y tras varias disposiciones lamentables, con las que intentó neutralizar o atemorizar a los ilirios de manera estúpida ${ }^{16}$, acaba siendo asesinado por un simple soldado raso, enviado por el Senado ${ }^{17}$. La ciudad está abierta.

En relación con este momento histórico concreto, la Historia Augusta, recoge a su vez un pasaje inquietante y curioso, que ofrece, entre otras cosas, la opinión que este autor (o autores) de rango senatorial tenía(n) acerca de las tropas de Severo, y del mismo modo muestra muy a las claras la actitud endeble y vacilante de Didio Juliano y de sus escasos partidarios frente la llegada de las legiones danubianas a la Ciudad: «Al conocer estas cosas, Juliano pidió al senado que las vírgenes Vestales y todos los

\footnotetext{
10 AMIANO MARCELINO, XXX 7, 2.

11 AMIANO MARCELINO XXV 10, 13.

12 HERODIANO II $9,11$.

13 DIÓN CASIO LXXIV 15,2.

14 HERODIANO II 6, 6; HISTORIA AUGUSTA, Didio Juliano 9, 1-2.

15 HERODIANO II $11,7$.

16 HERODIANO II $11,9$.

17 HISTORIA AUGUSTA, Didio Juliano 8, 8.
} 
sacerdotes salieran junto con los senadores al paso del ejército de Severo y le imploraran con sus cintas desplegadas hasta el suelo, adoptando así una...medida inútil contra un ejército de bárbaros» ${ }^{18}$.

Acto seguido, tras afianzar la situación en la capital, castigando a los asesinos de Pértinax y realizando una purga en el cuerpo de los pretorianos ${ }^{19}$, vemos a Severo marchar contra su segundo rival, un antiguo amigo de la juventud como era Pescenio Níger ${ }^{20}$.

\section{Severo y la Invasión de Siria}

Níger, que era un gran general, gozaba de mucha popularidad entre el pueblo y el senado de Roma, y la provincia en la que en ese momento le sorprendieron los acontecimientos, Siria, le era enormemente adicta, en especial su capital, Antioquia. Aquí encontramos otro pasaje muy esclarecedor de Herodiano, valorando en su justa medida el apoyo de la juventud siria, que en masa se alista y forma un ejército para Níger. Sopesando de manera sagaz y realista el valor real de estos apoyos, vemos que a las fuerzas de este emperador se ha sumado una muchedumbre vehemente, pero volátil y frívola, sin experiencia en la guerra o las fatigas. Este es el sobrio y acertado juicio del historiador griego sobre la balanza militar de la campaña oriental en 194: [...] Níger, que había reunido un ejército numeroso, aunque falto de la experiencia que dan el combate y las penalidades [...]. Ciertamente, el entusiasmo de su ejército era un soporte para Níger, pero en experiencia y en valor quedaban muy por debajo de los ilirios $»^{21}$. De hecho, la invasión de Siria y Asia Menor por parte de Severo fue un éxito ${ }^{22}$; salvo el revés sufrido ante el paso del Tauro, sólo Bizancio resistió enconadamente hasta 197. Níger desde el principio se quedó insensatamente encajonado en Asia y Siria, y esta coyuntura, unida al hecho de que no se preocupó en ganarse la lealtad de los numerosos y excelentes soldados ilirios, le ganaron los reproches de Herodiano por su indolencia fantasiosa ${ }^{23}$. La campaña oriental finalizó con una vic-

18 HISTORIA AUGUSTA, Didio Juliano 6, 5. Dependiendo de la fecha de redacción o revisión definitiva de esta obra, podríamos hallarnos ante la desesperanzada actitud de la clase aristocrática senatorial pagana, que asistiría deprimida y angustiada a la llegada de los bárbaros a Roma en el siglo V (un eco quizá del saqueo de 410 ó 455).

19 HERODIANO II 13; DIÓN CASIO LXXV 1, 1-2. Este cuerpo sufrió entonces unas profundas y radicales transformaciones, y ya nunca volvió a ser el mismo. El emperador Constantino I finalmente los disolvió (312).

20 Cayo Pescenio Níger, de familia ecuestre, uno de los generales más importantes de Roma en los reinados de Marco Aurelio y Cómodo; también fue gobernador de Dacia (188-190) y posteriormente de Siria.

21 HERODIANO III $4,1$.

22 DIÓN CASIO LXXV 6-8; HERODIANO III 2-4, III 6, 8-9.

23 HERODIANO II 9-10. 
toria para las tropas de Severo, que triunfaron en Nicea, Cízico y en la descomunal y sangrienta batalla de Iso, que Herodiano compara a la acontecida siglos atrás en el mismo lugar entre Alejandro Magno y Darío III. En esa batalla final, fueron precisamente los ilirios los que rompieron la línea de batalla de las fuerzas de Oriente, logrando así un triunfo incontestable y avasallador ${ }^{24}$. Severo se mostró punitivo y cruel con las ciudades partidarias de Níger, y benévolo y generoso con quienes le habían sido fieles ${ }^{25}$. Los sirios, habituados a las fiestas y a una vida llena de lujo y placeres, no fueron rivales globalmente para las duras legiones de Iliria y Panonia, pese a ser considerados un pueblo despierto e inteligente ${ }^{26}$. Tras el fin de las hostilidades se preparó un castigo especialmente duro contra la capital de la provincia, cuyos habitantes lenguaraces y dados a la burla ${ }^{27}$ sufrieron ahora cumplida venganza del vencedor, un militar de espíritu irrefrenable ${ }^{28}$. A partir de dicho momento, esta actitud será la tónica habitual en el reinado, y el comportamiento de Septimio Severo pasará por estos accesos de crueldad muy a menudo ${ }^{29}$.

Ya se ha mencionado anteriormente que Severo fue un hombre intrépido, enérgico y lleno de recursos, y los sucesos que sucedieron a continuación lo demostraron una vez más. En 193 había engatusado con promesas y halagos a un potencial rival para el Imperio, que de hecho estaba a punto de proclamarse en Occidente; este no es otro que Albino ${ }^{30}$, un personaje de familia noble oriundo de África, al igual que Severo. Durante algún tiempo, colaboró con Septimio Severo recibiendo el rango de César, pero una vez que el Oriente quedó subyugado tras la liquidación de Níger, Albino se convirtió en una molestia, y Severo comenzó a buscar la manera de librarse de él para poder afianzar en el poder a sus hijos. Tras varios intentos fallidos de asesinato, no le quedó más remedio que organizar una campaña militar para marchar a la Galia y acabar allí con él ${ }^{31}$. Parece que la ruptura definitiva entre ambos ocurrió en 195, pero no se alzarán las espadas hasta dos años después, cuando los preparativos estén terminados.

24 HERODIANO III 4, 5.

25 Tiro y Laodicea se vieron ricamente premiadas, Antioquia y Beirut recibieron duros castigos (Cf. HERODIANO III 6,9).

26 Otra digresión etnográfica más en HERODIANO III 11,8.

27 HERODIANO II 10, 7.

28 HISTORIA AUGUSTA, Severo 9, 4. HERODIANO, III 6, 9. Para la actitud ciertamente inconsecuente y excesiva de los antioquenos hacia los emperadores, AMIANO MARCELINO XXII 14, 2.

29 HISTORIA AUGUSTA, Severo 18, 7; 21, 10; HERDODIANO III 8, 8; AURELIO VÍCTOR 20, 11-14; DIÓN CASIO LXXVI 7, 4.

30 Décimo Clodio Albino, de familia noble africana. Nacido en Hadrumetum, estuvo al mando de las tropas en Bitinia, y posteriormente fue gobernador de esa misma provincia (175). Ejerció el consulado junto a Severo en 194.

31 HERODIANO III 5, 2-8. 


\section{Guerra en Occidente. Batalla de Lyon}

En esta ocasión, no obstante, las legiones de Severo van a someterse a una dura prueba, pues las tropas que servían a Albino en Galia, Hispania y Britania podían competir perfectamente en cualidades militares con ellas ${ }^{32}$. Parece que la superioridad numérica estaba de parte de Septimio Severo, que también gozaba de la iniciativa y de una ligera ventaja estratégica, ya con la mayor parte de las provincias bajo su control directo, pero aun así, la empresa no se presentaba nada fácil, y de hecho las primeras escaramuzas y los combates iniciales se decantaron en victorias para Albino $^{33}$. Severo, nuevamente mostrándose como un gran conocedor de los asuntos bélicos y un líder consumado, arengó antes de la campaña a sus soldados, dándonos así de paso otro espléndido y colorido ejemplo de la forma de vida y aptitudes de las tropas ilirias: «Vosotros os habéis ejercitado en el campo de batalla en vuestros continuos combates contra los bárbaros, y estáis acostumbrados a soportar todo tipo de fatigas, a despreciar fríos y calores, a cruzar ríos helados y a beber agua teniendo que romper el hielo en lugar de sacarla simplemente de un pozo; también os habéis ejercitado en el arte de la caza. Y contáis con tan excelentes recursos para el valor, que nadie, aunque quisiera, os podría hacer frente» ${ }^{34}$.

De hecho, Albino parece que no se comportó como un rival de entidad, y de cualquier modo su carácter prepotente y vanidoso le convirtió, en primer lugar, en un personaje manejable y dócil gracias a las lisonjas, y posteriormente en un oponente descuidado y poco diligente ${ }^{35}$. No obstante, las tropas que iban a combatir por él eran completamente distintas a su caudillo, y Severo mismo lo sabía; trató, una vez más, de insuflar los ánimos de sus soldados. Era el momento de recordar las victorias pasadas y hablarles de su posición ventajosa, quitando importancia a las primeras derrotas y al valor y pericia que poseían los combatientes galos y britanos: «Su pequeño ejército insular no resistirá vuestra fuerza. Vosotros, que solos y por vuestro propio arrojo y valentía habéis vencido en tantas batallas y habéis sometido todo el Oriente, ahora precisamente, cuando tenéis a vuestro lado a tan notables tropas auxiliares y cuando está aquí casi todo el ejército romano, ¿cómo no vais a vencer fácilmente a un escaso ejército que no está dirigido por un hombre valeroso y sobrio [Albino]?»36.

El ejército de Severo llegó frente a Lugdunum (Lión), una ciudad muy grande e importante de la Galia, donde se había reunido la hueste de Clodio Albino. Las tropas a su mando incluían las tres legiones britanas, efectivos galos en abundancia

32 HERODIANO II $15,1$.

33 DIÓN CASIO LXXVI 6, 2-3. HISTORIA AUGUSTA, Clodio Albino 9, 1.

34 HERODIANO II 10, 5.

35 HERODIANO II 15, 3; III 7,1; HISTORIA AUGUSTA, Clodio Albino 11, 2-8.

36 HERODIANO III 6, 6. 
y posiblemente también las fuerzas hispanas, llegadas hasta allí para tomar parte en ese crucial momento ${ }^{37}$. Nos encontramos en el diecinueve de febrero de 197. El choque comienza con fuerza, una vez que ambas huestes han formado frente a frente. Herodiano da fe de la bravura de los soldados de Occidente, en especial de las tropas insulares, y pronto veremos que su inferioridad numérica no se muestra como un factor decisivo: «Los britanos por su valor y su espíritu sanguinario no iban a la zaga de los ilirios, y la consecuencia de combatir dos excelentes ejércitos era que no fuese fácil la derrota de ninguno $»^{38}$.

En cuanto a los galos, el historiador Amiano Marcelino nos da otro vivo ejemplo de sus características bélicas; pese a hablar y escribir sobre acontecimientos que ocurrieron doscientos años después del episodio que estamos tratando, ofrece una descripción que es totalmente válida para discernir su gran potencial como combatientes: «Casi todos los galos son de gran estatura, de piel blanca, cabello rojizo, con aspecto terrible por la dureza de su mirada, ávidos de pelea y de un orgullo extre$m o »^{39}$. Para proseguir: «Cualquier edad les parece adecuada para la lucha, y tanto el anciano como el adulto se preparan para el combate con similar vigor, con los miembros endurecidos por el hielo y por el trabajo continuo, dispuestos a despreciar todo lo que se les ponga por delante, por temible que sea. De hecho, entre ellos ninguno se ha cortado nunca el pulgar por temor a la guerra, como sí sucede en Italia, donde forman el grupo que denominan allí «murcos» [mutilados]».40

Con tales características, las tropas de Albino cargaron hacia sus enemigos llenos de furia, y no es de extrañar que incluso los fuertes y combativos ilirios se viesen en apuros frente a tal avalancha; parece que en algún momento la izquierda de Albino perdió terreno y finalmente se retiró hasta sus campamentos, pero en cambio su derecha, seguramente por encontrarse allí sus fuerzas más selectas y escogidas, realizó una fenomenal proeza, barriendo el ala izquierda del enemigo, posición donde se encontraba el mismo Severo. Herodiano nos deja un pasaje muy revelador y descriptivo acerca de lo ocurrido: [...] «la línea de combate del ejército de Albino fue muy

37 J. TORRES ESBARRANCH en su nota 238 a la edición de HERODIANO (Madrid, 1985), da por segura la participación el esta batalla de la hispana Legión VII Gemina, mientras que J. ARCE (España entre el Mundo Antiguo y el Mundo Medieval. Madrid 1988, p. 51) lo niega, alegando que Quinto Mamilio Capitolino, comandante de esta unidad, se mantuvo fiel a Severo.

38 HERODIANO II 7, 2.

39 AMIANO MARCELINO XV 2, 1.

40 AMIANO MARCELINO XV 12, 3. Existe una abundante y muy conocida documentación legal acerca de la práctica de cortarse los pulgares para eludir la llamada a filas; los continuos quebraderos de cabeza que estos sucesos ocasionaban a los emperadores concluyeron finalmente en la ley de 367 , que obligaba a realizar el servicio militar, aun con los dedos amputados (Codex Theodosianus 7 13, 3). Al año siguiente, seguramente por la pervivencia de esta costumbre, se decretó una drástica medida: quien realizase tales acciones debería ser quemado vivo (Codex Theodosianus 7 13, 4). 
superior por la parte en que Severo y sus tropas estaban situados, hasta el extremo de tener que ponerse a salvo. En su huída fue derribado del caballo, pero pasó desapercibido porque se había desprendido de su manto imperial». Unas trampas muy bien disimuladas en el campo de batalla, contribuyeron a la confusión y carnicería en las tropas danubianas ${ }^{41}$. El mismo Severo se libró de sus atuendos regios viendo como sus huestes se batían en retirada y los britanos pululaban por todas partes matando a diestro y siniestro; arma en mano intentó recuperar la formación, o al menos salvar la vida No obstante, lo que estaba a punto de convertirse en una victoria aplastante para Albino, cambió repentinamente de signo con la entrada en escena del general Julio Leto con las tropas de reserva, la caballería. Parece que su deseo no era ayudar a Severo, su señor, al que creía muerto, si no más bien apoderarse del poder imperial para sí, pues pensaba que con toda posibilidad también perecería Albino ${ }^{42}$. Después de la batalla, de hecho, Septimio Severo recompensó largamente a sus generales y tribunos, pero a Leto lo condenó a muerte y ejecutó posteriormente, lo que confirma esta versión, aunque Dión Casio nos diga lo contrario ${ }^{43}$. A continuación, asistimos al reverso de la situación: «Cuando los britanos ya iniciaban la persecución y cantaban el himno de la victoria, pensando que ya habían vencido, apareció Leto, un general de Severo, con las tropas a sus órdenes que estaban frescas por haber permanecido fuera de la batalla».44

Está claro que las cosas hubiesen acabado muy mal para Septimio Severo de no ser por esta intervención milagrosa de última hora; su subordinado, aunque actuase sólo por pura y simple ambición, de hecho salvó a Severo. Las tropas ilirias recobran la moral tras la súbita llegada de refuerzos, y comienzan a reagruparse: [...] «y las fuerzas de Severo se animaron; colocaron a Severo en su caballo y le pusieron su manto». ${ }^{45}$

El destino de la batalla estaba sellado. Las huestes de Albino se encuentran repentinamente estupefactas y desorganizadas, y el contraataque ilirio resulta devastador. [...] «Después de resistir durante un breve tiempo, abandonaron y se originó una retirada desesperada en la que las tropas de severo los siguieron en una persecución sangrienta hasta que se refugiaron en la ciudad». ${ }^{46}$

41 DIÓN CASIO LXXVI 6, 4.

42 Leto no sabía que Albino había permanecido dentro de las murallas de Lión sin participar en la batalla; del mismo modo, por medio de los soldados o de los heridos, tuvieron que llegarle rumores de que se había visto el caballo de Severo enjaezado con las insignias imperiales vagando sin jinete en medio del desastre, lo que le inclinó a actuar.

43 DIÓN CASIO (LXXVI 10. 3) achaca la medida tomada por Severo a la gran popularidad de Leto entre los soldados y sus grandes dotes de mando, pero está claro que el motivo fue este flagrante intento de traición que no había sido olvidado. Leto fue ejecutado en Oriente en 199.

44 Todo este pasaje y el anterior se encuentran en HERODIANO II 7, 4.

45 HERODIANO II 7,5.

46 HERODIANO II 7,6. 
A continuación tuvo que realizarse una decidida masacre; sabemos que los soldados de Severo saquearon y prendieron fuego a Lugdunum. Allí, al conocer la debacle, se suicidó Albino, siendo llevado después su cadáver ante Severo ${ }^{47}$. Pero cabe destacarse, como conclusión a esta batalla, como un ejército inferior en número y dificultado por una situación poco ventajosa, estuvo a punto de hacerse con la victoria. Resulta significativo que las tropas britanas entonasen un cántico de triunfo cuando vieron la pugna decantarse a su favor: evidentemente, las costumbres y usos celtas para la guerra se habían conservado en gran medida dentro de estas tropas, y seguramente también existieran pervivencias menores en el armamento y el modo de combatir. En cualquier caso, el espíritu indómito, salvaje y ajeno al miedo de los celtas, que ya los hicieron tan valiosos como mercenarios desde la época de los cartagineses, todavía no se había perdido. Pero delante tenían a un oponente también decidido y más numeroso, y del calibre de las legiones panonias.

\section{Las campañas orientales}

Después de someter todo el Imperio Romano a su dominio, Septimio Severo se dirigió de nuevo al Oriente; el pretexto que utilizó para esta campaña militar residía en castigar a algunos reyes fronterizos que habían ofrecido su apoyo a Níger en la guerra civil, pero no parece raro que Herodiano esté en lo cierto cuando dice que realmente quería añadir un éxito a su palmarés, en este caso contra enemigos extranjeros, para que no se le recordase solamente como el vencedor de los conflictos intestinos, donde había mucha sangre romana y ejecutado gran cantidad de hombres distinguidos y de alta alcurnia ${ }^{48}$.

Vamos a centrar estas primeras campañas en una breve panorámica los dos asedios de Hatra, en 198 y 199; el posterior saqueo «casual» de la capital de los partos y la gran matanza que allí causó van a quedar en un segundo y oscuro plano, para poder estudiar mejor algunos pasajes que muestran la actuación que tuvieron las legiones ilirias en este nuevo marco estratégico. Parece que en los desiertos de más allá del limes, el calor y las condiciones climáticas tremendamente adversas mellaron seriamente la capacidad operativa de estas tropas, que naturalmente no estaban acostumbradas a semejante paisaje. Los asedios a la fortaleza de Hatra van a ser rechazados con pérdidas, y los ilirios, invencibles bajo Severo hasta ese momento, van a sufrir un serio quebranto; después de tantas victorias, el no haber podido tomar esas fortificaciones les supo a todos más como una derrota que como un fracaso. El clima y los insectos de la zona añadieron aún mayor sufrimiento a los soldados, formando un

47 DIÓN CASIO LXXVI 7,3.

48 Una lista de las víctimas aparece detallada en HISTORIA AUGUSTA, Severo 13, 1-8. 
tormento difícil de superar y que multiplicó las bajas: «Y al no soportar la sofocante atmósfera a causa de la excesiva irradiación solar, caían enfermos y morían [...]».49

En cierta medida, el saqueo de Ctesifonte y la mortandad producida posteriormente entre los partos pudo saciar y reconfortar a las tropas de Severo, que regresó al territorio romano como un general victorioso. Severo volvió a Roma, donde le esperaba una existencia nada cómoda, y un ambiente enrarecido y preocupante, viciado de desconfianza por las múltiples conspiraciones ${ }^{50}$. Tras varios años de estancia en el continente, tuvo que partir a Britania para auxiliar a las fuerzas romanas de la provincia, que sufrían graves ataques y rapiñas constantes por parte de los bárbaros del norte. Es de suponer que estos mismos contingentes ilirios acompañaron también al emperador en su campaña contra los pictos de 208. Tras pasar casi cuatro años en la isla, morirá allí, ya muy anciano y aquejado de gota, en Eboracum (York). Dejaba al mando de un Imperio Romano pacificado y seguro a sus dos hijos, Geta y Caracalla, que se odiaban profundamente.

\section{Los sucesores de Septimio Severo}

Tras la breve y feroz pugna que mantuvieron los hijos del emperador a la muerte de su padre en 211, Geta es asesinado y muy pronto Caracalla se vio como señor único del Imperio. Su actitud hacia los soldados (al igual que su padre, les aumentó las pagas) y su indumentaria de simple legionario, la vida sencilla y austera, y el esfuerzo continuo en las marchas a pie y los trabajos cotidianos de la vida en campaña tuvieron que hacer de este emperador una figura hacia la que los soldados, especialmente los ilirios, volcaran toda su adoración ${ }^{51}$. Caracalla emuló a su padre el la hostilidad desmedida de su política exterior hacia el Reino Parto, y en 216-217 lo vemos dirigir una nueva campaña en el Oriente. Los contingentes ilirios de seguro tuvieron que estar presentes una vez más, pero el complot ideado por Macrino para eliminar al emperador y ocupar su lugar ocupa muy pronto la atención de las fuentes, y los acontecimientos bélicos pasan a un segundo plano. De cualquier modo, tras la muerte de Caracalla en 217, Macrino se apresura a sellar una nueva paz con los partos y regresa a Antioquia, que se convierte en una capital imperial durante su breve reinado. Su programa político, diametralmente opuesto al de los Severos, no pudo llevarse a cabo porque también fue asesinado ${ }^{52}$.

49 HERODIANO III 9, 6. También HISTORIA AUGUSTA, Severo 16, 2.

50 HERODIANO III $12,11$.

51 HERODIANO IV 7, 2-7. Caracalla además logró derrotar a los alamanes (cf. AURELIO VÍCTOR 21, 2).

52 Marco Opelio Macrino, el primer soberano imperial de clase ecuestre. Un fantástico estudio del reinado de este emperador en E. PASOLI, Opilius Macrinus/Iulius Capitolinus; Bolonia, 1968. 
Después de la pausa estrambótica y delirante de Heliogábalo, nos encontramos con que Severo Alejandro, el último emperador de esta dinastía, debe volver a Oriente para salvaguardar las fronteras romanas y defender el orden y la integridad de sus territorios contra un renovado y agresivo poderío persa, que tras 224 se lanzó a una serie de campañas contra el Imperio Romano, con su rey Artajerjes I (m. 241) a la cabeza $^{53}$. Era este emperador un joven moderado y benévolo, con una excelente educación griega y romana, pero sometido de tal manera a la insidiosa vigilancia de su madre Julia Mamea que las fuentes antiguas lo culparán a menudo por esta situación chocante e incluso vergonzosa ${ }^{54}$. Una vez más, Antioquia se convertirá en el centro de operaciones y cuartel general de las fuerzas romanas, y al parecer el ambiente lujoso y distendido de la bella ciudad atrajo en demasía al joven Alejandro, amante de las carreras de carros y los lujosos placeres de esa capital; todo esto se le reprochará duramente al final ${ }^{55}$. Pero inicialmente, parece que el emperador se mostró activo y competente, y preparó la invasión del territorio enemigo con ahínco y duro trabajo, emulando las cuitas de su antecesor y fundador de la dinastía. Curiosamente, el plan de ataque forjado en este momento es casi idéntico al plan del emperador Juliano para su campaña persa de 363: tres columnas romanas se adentrarían en tierras enemigas, una, las más poderosa e importante, comandada por el propio emperador, marcharía directamente a la capital enemiga, mientras que dos columnas auxiliares en los flancos (uno de ellos saliendo desde Armenia) pondrían en jaque al masificado ejército parto feudal, creando una superioridad táctica y numérica en cualquier situación de combate real. La amenaza para los persas era mortal si los movimientos se realizaban con esmero y sincronización; pero en este caso, como después en tiempos de Juliano, los movimientos no se realizaron con rapidez y, algo más grave todavía, los diferentes cuerpos no se apoyaron entre sí. En el siglo IV fue el cuerpo principal de Juliano, con 60.000 hombress, el que se quedó extraña y sospechosamente solo; en esta ocasión, Severo Alejandro se quedó atrás, y de manera inexplicable abandonó a su suerte a las dos otras columnas, siendo una de ellas masacrada por los persas, mientras que la otra tuvo que replegarse precipitadamente por terrenos montañosos, sufriendo muchas bajas por congelación y por la aspereza del terreno. Solamente las grandes perdidas sufridas por los persas en la batalla que llevó a la aniquilación de la columna romana aislada, que vendió muy cara su piel una vez abandonada y condenada a la destrucción, evitó una rápida invasión de Siria tras la ruinosa ejecución de las opera-

53 Marco Aurelio Severo Alejandro. Las hostilidades comenzaron en 232.

54 HERODIANO VI 1,5; VI 9, 4.

55 HERODIANO VI 6, 6; 7, 10. 
ciones $^{56}$. Y los males no acabaron allí. El mismo cuerpo principal de Alejandro había sufrido muchas bajas por los largos desplazamientos y el duro clima, y los contingentes ilirios vuelven a sufrir todo el rigor del desierto en sus carnes, convirtiendo cada marcha en una pesadilla. El emperador, finalmente consciente del desastre que había causado $^{57}$, se sintió desfallecer y enfermar, según cuenta Herodiano. No era el único: «También estaba enfermo todo el ejército; pero sobre todo los soldados ilirios que, al estar acostumbrados a un clima más húmedo y fresco y habituados a comida más abundante, se ponían muy enfermos y morían». ${ }^{58}$

En este momento, una coyuntura espacio-temporal tremendamente desafortunada, en la frontera danubiana, provocó un acontecimiento que finalmente resultó catastrófico para Alejandro Severo: una incursión de germanos saqueó y devastó amplias zonas de Panonia y el Ilírico, con gran ruina y mortandad para estas regiones. Naturalmente, para el grueso del ejército estacionado ahora en Siria, que era oriundo de esas provincias, la catástrofe fue igual o más dura que sus propios sufrimientos tras la derrota: «Estas noticias inquietaron a Alejandro y afligieron a los soldados de Iliria al pensar que habían sufrido una doble desgracia, una por sus padecimientos en la guerra contra los persas y otra por las noticias que cada uno había recibido sobre sus familiares muertos por los germanos». ${ }^{59}$

Las tropas habían perdido la confianza en su emperador. Comenzarán a echarle en cara su amor por los placeres, la obsesiva e insidiosa influencia de su omnipresente y codiciosa madre, su pusilanimidad y la ruina que había hecho caer sobre todos ellos ${ }^{60}$. Pero el ejército marchará hacia Occidente a regañadientes, dispuesto a tomarse la revancha, especialmente las legiones ilirias y panonias. Pero las cosas no van a resultar como ellos esperaban; Alejandro Severo prefería terminar con las depredaciones de los germanos usando oro, por la vía diplomática, para que regresen a sus tierras. En ese momento, estalla la cólera contenida de los soldados que deseaban ardientemente luchar contra los saqueadores e incursotes de sus hogares. Frente aun soberano débil

56 En cambio, y de manera sorprendente, la HISTORIA AUGUSTA (Severo Alejandro 57, 2) niega total y explícitamente a HERODIANO (VI 6, 5-6), desacreditando esta versión de los hechos y otorgando una victoria total contra los persas (Id. 55 1-2). AURELIO VÍCTOR 24 y EUTROPIO VIII, 23 también se mencionan victorias romanas. El desarrollo posterior de los acontecimientos, no obstante, mueve a tratar estos triunfos con suma cautela, pues no resulta coherente la trama contra Alejandro si se hubiese conseguido una aplastante victoria militar de tales proporciones.

57 No está claro por qué Alejandro Severo actuó de esa manera en la campaña persa; HERODIANO lo atribuye bien a la mala influencia de su madre, o bien a que flaqueó por propia cobardía (cf. VI 9, 5; VI 9, 8).

58 HERODIANO VI 6, 2.

59 HERODIANO VI 7, 3.

60 HERODIANO VI 7, 4. 
y poco belicoso, disfrutaban con el ejemplo diario de Maximino ${ }^{61}$, que había sido nombrado comandante de alto rango recientemente; este tracio, antiguo pastor, un $\mu \xi_{o} \beta \alpha \rho \beta \alpha \rho \circ 5$, de físico gigantesco y fortaleza hercúlea, encarnaba a la perfección el ideal de príncipe que las legiones requerían en ese momento. Famoso por sus proezas militares y su maestría en combate, predicaba con el ejemplo, y siempre se lanzaba al combate a la cabeza de sus soldados ${ }^{62}$. Su linaje bajo y la incultura total de la que adolecía no importó a nadie. Es más, la destreza con las armas de éste se convirtió en un señuelo infalible para maquinar un complot y elevarlo al poder, y su fiereza en la guerra pronto desbancó a la probidad y grandes conocimientos del refinado Alejandro. La tropa ya tenía un nuevo ídolo: «Por esto los jóvenes, que en su mayor parte eran de Panonia, elogiaban el valor de Maximino mientras se burlaban de Alejandro porque estaba a las órdenes de su madre». ${ }^{63}$

El emperador fue desposeído del poder y asesinado junto a su madre y allegados. Maximino es revestido con la púrpura y proclamado Augusto. En el año 235, el primer emperador-soldado entra en escena.

\section{Conclusión}

Tras el controvertido reinado de Maximino el tracio, que pareció a su vez asesinado por sus exasperadas tropas en 238, asistimos a lo que se ha denominado a menudo el revival senatorial de 238-244, donde encontramos hasta cinco emperadores pertenecientes o nombrados por el Senado de Roma (los Tres Gordianos, Máximo y Balbino). Pero esta tentativa pronto queda difuminada ante el ascenso imparable del poder de los prefectos del pretorio, y quedará muy claro que ellos, y principalmente los soldados, tienen en sus manos las llaves de palacio, y que realmente son los que deciden quién se revestirá de la púrpura imperial o no, y quien debe dejar de llevarla.

En esta coyuntura, las legiones danubianas van a convertirse en la clave del panorama político y militar, y resultarán imprescindibles tanto para derrotar y expulsar a la creciente ola de pueblos bárbaros como para combatir el las guerras civiles y los sangrientos conflictos internos que arrasarán el Imperio Romano hasta la subida al trono de Diocleciano en 284. Serán las tropas ilirias las que, bajo el mando de Decio, derroten a los bárbaros en el Danubio, y posteriormente proclamen emperador a su victorioso general. Las mismas legiones vencerán sin problema alguno en la confla-

61 Cayo Julio Vero Maximino; su origen rústico no fue obstáculo para que desarrollase una fulgurante carrera militar plagada de ascensos desde la milicia base hasta los más altos escalafones (HERODIANO VI 8,1$)$.

62 HERODIANO VII 2, 6-7.

63 HERODIANO VI $8,3$. 
gración siguiente, aplastando junto a Verona en 249 al ejército de Filipo el Árabe, un emperador intrépido que tratará de reunir un ejército y sofocar la rebelión, pero que va a comprobar como sus tropas italianas junto a su propia guardia imperial son barridas por un adversario muy superior. Filipo morirá en el campo de batalla ${ }^{64}$.

Los godos conseguirán algunas victorias a continuación, pero la historia se repite y en 253 encontramos a las mismas legiones derrotándolos completamente, y proclamando también emperador en esta ocasión a su líder, Emiliano, que asimismo será asesinado poco después. Pero las tropas ilirias continuarán con sus logros, y por fin podrán tomarse una cumplida venganza de todas las penalidades sufridas en el frente persa derrotando a Sapor I en el mismo 253, donde un ejército invasor quedó destruido junto a Emesa; en 263 encontramos nuevas e importantes victorias en Oriente. También serán cruciales en la victoria completa de Galieno sobre los alamanes en Milán (259), en la victoria de Claudio II sobre ese mismo pueblo en el lago Garda (268) y en la aniquilación de una horda invasora de marcomanos llevada a cabo por Aureolo, magíster equitum en 269 y que posteriormente también conspiraría por el poder. Pero el apogeo total y absoluto de las legiones ilirias llegará cuando bajo el mando del emperador Claudio II derroten en $\mathrm{Naiso}^{65}$ (269) a los godos, obteniendo una espectacular victoria en la que 50.000 enemigos quedaron abatidos; por primera ocasión, un emperador romano obtendrá el sobrenombre de Gótico. En 296, otro gran ilirio, Galerio, infligirá una aplastante derrota a los persas, resarciéndose Roma de este modo de la captura y muerte en cautiverio de Valeriano ${ }^{66}$.

En definitiva, las nuevas fuerzas romanas de primera línea, la infantería pesada y las legiones más preparadas para el combate, se encontrarán a partir de ahora en Iliria y Panonia, donde los generales brillantes, quizá por este mismo motivo, comenzarán también a proliferar, al mando de las tropas más hábiles y adiestradas. Italia, de este modo, se verá desplaza definitivamente de la preponderancia en el plano militar ${ }^{67}$.

64 EUTROPIO IX, 3; AURELIO VÍCTOR 28, 10.

65 OROSIO VII 23; ZÓSIMO I 43, 45; EUTROPIO IX 11, 2.

66 P. BROWN, El Mundo en la Antigüedad Tardía, de Marco Aurelio a Mahoma. Barcelona, 1989, p. 35 .

67 Resulta esclarecedora la mención sobre este aspecto de HERODIANO (II 11, 5). 